\author{
東海大学森山裕幸，村上俊太郎，获 三二 \\ Flow Patterns and Spectra of Noise Generated by Flow in Expansion Chamber \\ Mufflers with an Inner Pipe Respectively \\ by Hiroyuki MORIYAMA* , Shuntaro MURAKAMI*and Sanni HAG ${ }^{*}$
}

\begin{abstract}
The airflow patterns in the cylindrical expansion-chamber mufflers inserted with an inletpipe or a tailpipe respectively were visualized by spark-tracing and smoke-wire methods. Next the spectra of sound pressure levels (SPLs) of the flow noise generated secondarily in the mufflers were measured.

It is obvious from these experimental results that the frequency characteristics of flow noise change with the flow pattern determined by the ratio of the distance between either open ends of an inserted pipe and a chamber to pipe diameter. The SPLs for the tailpipe-inserted mufflers show moderately high values in the wide range of frequency as compared with those of the inletpipe-inserted mufflers, owing to the occurrence of the recirculation flow in the surroundings of the inner pipe.
\end{abstract}

1. 藉言

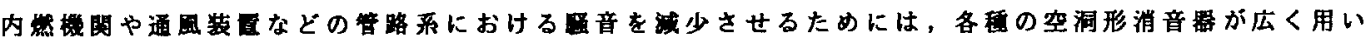
られている。特に，空洞内の入口管あるいは尾管を捅入したタイプの消音器は，空洞部の反射好果と管捅 入部の共鳴协果によりすぐれた消音特性が得られるのでよく用いられる。しかしこれらの消音器では内部 の気流によって発生する二次音のために，所要の音特性が得られない㧹合がある。したがって消音器 を設計する祭に，このような気流盈音についても十分に考豧する必要がある。

そこですこれらの捕入管のある消音器内の流九の樈子を把暒するために火花追跡法とスモークワイヤ

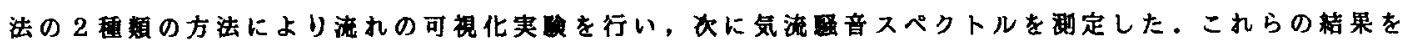

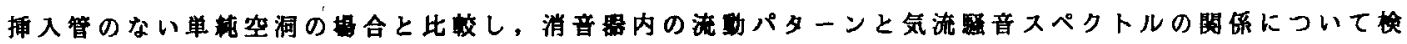
討した。

2 . 実唤粘果

$2 \cdot 1$ 消音器内の流扎の可視化

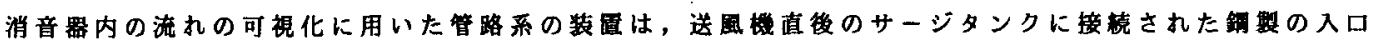
管（直径 $\mathrm{d}=48 \mathrm{~mm}$, 直管部長さ

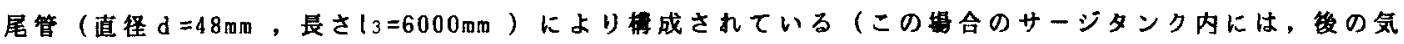

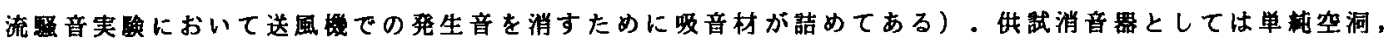
入口管㨉入空洞, 尾管挿入空洞の 3 種類の形状のものを用い, それらの寸法については拡大比 $\mathrm{m}(=$

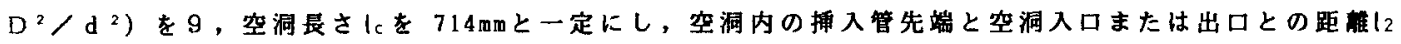
を璉々に変化させた。なお管内の平均気流速度 V は, 消音器入口の前方1200m位圈でピト一管により測 定した。

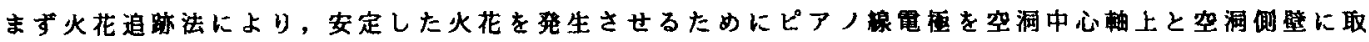
付け，中心軸を含む面に対な半円简部分の可視化を行った。撮影条件は流速 $\mathrm{V}=30 \mathrm{~m} / \mathrm{s}$, パルス間隔 $\mathrm{T}=$

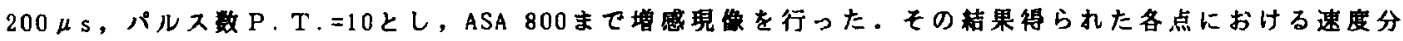

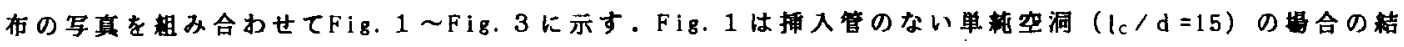
果を示している.空洞内に入った噴流は下流へ行くにしたがい半径方向に应散し, 流路の搪大に伴い流速 の低下がみられる。噴流が空洞㑡壁まで搪散し再付着流九になると流速は大きく低下し空洞出口に達する

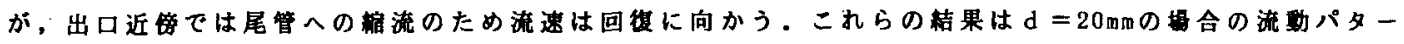
ン(1)とくらベて良い对度を示している.

* Faculty of Engineering, Tokai University, 1117 Kitakaname, Hiratsuka 


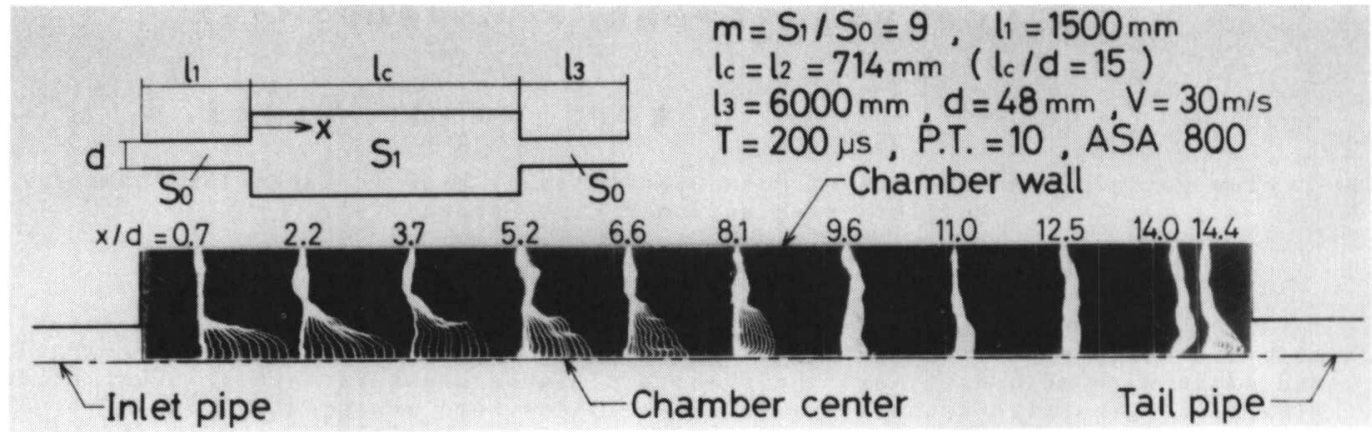

Fig. 1 Flow pattern in a single expansion chamber by spark-tracing method.
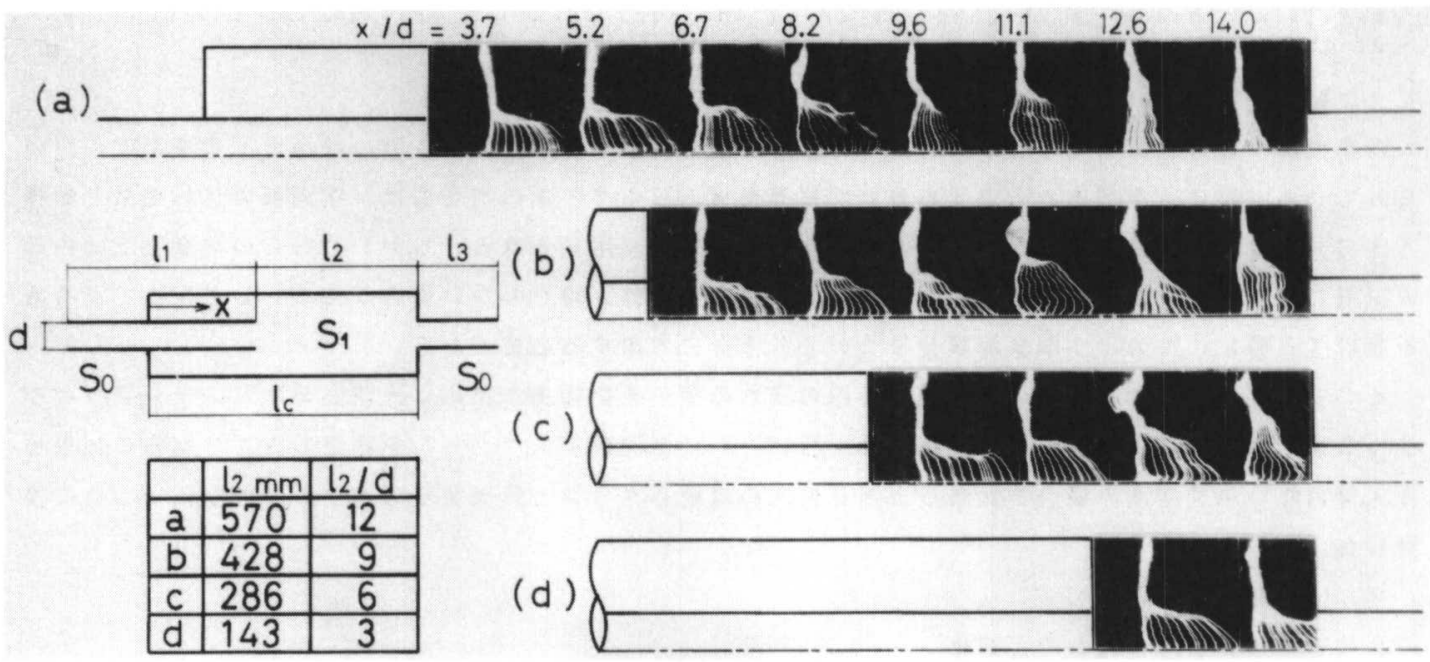

Fig. 2 Flow pattern in chambers inserted with an inletpipe by spark-tracing method.

(a)

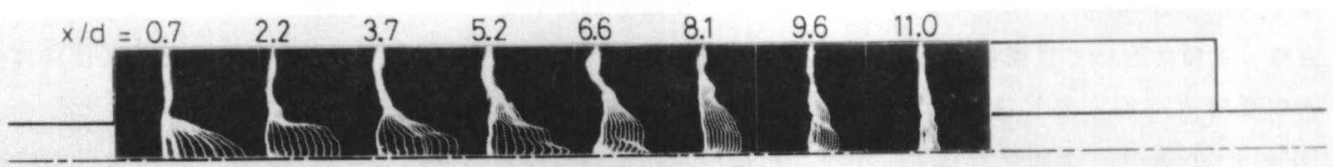

(b)

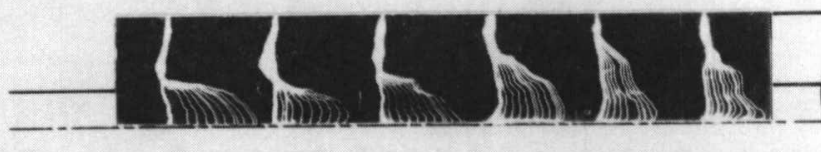

(c)
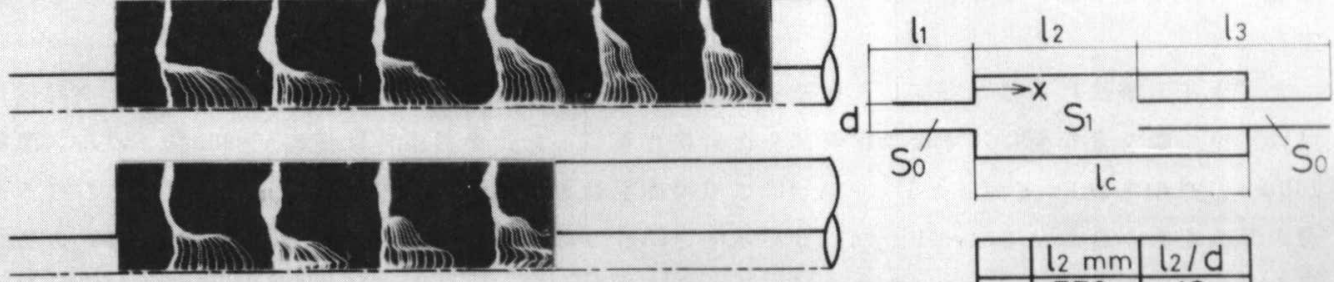

(d)

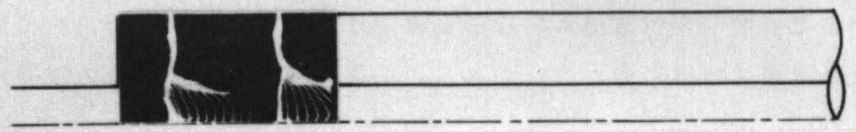

\begin{tabular}{|c|c|c|}
\hline & $l_{2} \mathrm{~mm}$ & $\mathrm{l}_{2} / \mathrm{d}$ \\
\hline $\mathrm{a}$ & 570 & 12 \\
\hline $\mathrm{b}$ & 428 & 9 \\
\hline $\mathrm{c}$ & 286 & 6 \\
\hline $\mathrm{d}$ & 143 & 3 \\
\hline
\end{tabular}

Fig. 3 Flow pattern in chambers inserted with a tailpipe by spark-tracing method. 
次に入口管择入空洞の場合の䊅果をFig. 2 に示す，入口管長さいが一定のため入口管から流入する嗔流 の速度分布は, 開口端間距醮 2 を変化させてもFig. 1 と同様の分布を示していることがわかる.まず開口 端間品離 12 が $570 \mathrm{~mm}(12 / \mathrm{d}=12$, (a)) のときにはFig.1のように再付着流れとなるので空洞出口近傍で の大きな流速低下がみられる。12 $3428 \mathrm{~mm}(12 / \mathrm{d}=9$ ，（b ））になると嗔流は空洞側壁まで拡散する前に 樎流となるため, 出口近傍の流速は(a)にくらべてかなり大きくなり, また再循環流領域における逆流も 顥著になる。12 が $286 \mathrm{~mm}(12 / \mathrm{d}=6,(\mathrm{c}))$ になると拡散の度合が小さくなるため, 空洞出口に達する啫 流の流速はさらに大きくなり，12が143m（12/d = 3，(d))になるとほとんと拡散がみられなくなる.

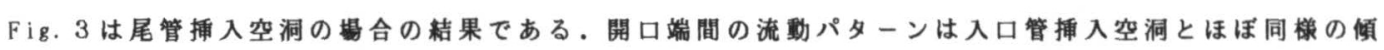
向で変化しており, また単純空洞の場合の変化にもおおむね対応している.しかしこれらの管を㨉入した 空洞では嘖流にくらへて流速の小さい流れが㨂入部に存在すると予想されるため, 次にスモークワイヤ法 により捕入部における流れの可視化も行った.

スモークワィヤ法の場合, ストロボ光をスリット状にし, パルス発生後数 $\mathrm{ms}$ 遅らせて可視化断面に発光 させる.このスリット光により発生したミストが可視化されるが,火花追跡法にくらべて光源が弱いため ASA 3200 まで增感現像を行い, 遅延時間 t も数種に設定した。その結果をFig. 4 ，Fig. 5 に示す．Fig. 4

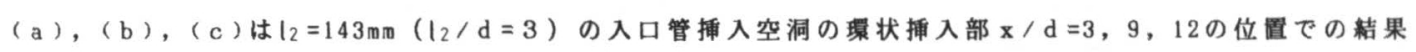
をそれぞれ示している. $\mathrm{x} / \mathrm{d}=3(\mathrm{t}=30 \mathrm{~ms})$ では流れが锶められないのに対し， $\mathrm{x} / \mathrm{d}=9(\mathrm{t}=30 \mathrm{~ms})$ では挿入管に沿った上流への流れとなっている．また $\mathrm{x} / \mathrm{d}=12(\mathrm{t}=6 \mathrm{~ms})$ すなわち入口管出口でも噴流 へ巻込む流れと上流への流れがみられる.たたしこれらの結果は1例で, 時間変動により種々の流れが製 察され,このような挿入部では旋回を含む複雑な三次元的流れになっているものと考えられ,これらの流 れは12を変化させ挿入部の長さを変えても同様に確認できた。さらに尾管挿入空洞の挿入部先端近䧛の結 果をFig. 5 に示す. 12 が570mm ( $12 / d=12, t=25 \mathrm{~ms}, 30 \mathrm{~ms})$ の場合，( a ）（b)のような 2 種類の尾管へ の流入模様が確認できたが,これらの流れも不安定で流入経路は時間的に変化している.それに対しにが $143 \mathrm{~mm}(12 / \mathrm{d}=3, \mathrm{t}=15 \mathrm{~ms})$ では(c)のように尾管への流入がほとんど認められず, 空洞側壁近くで逆流 が生じている.

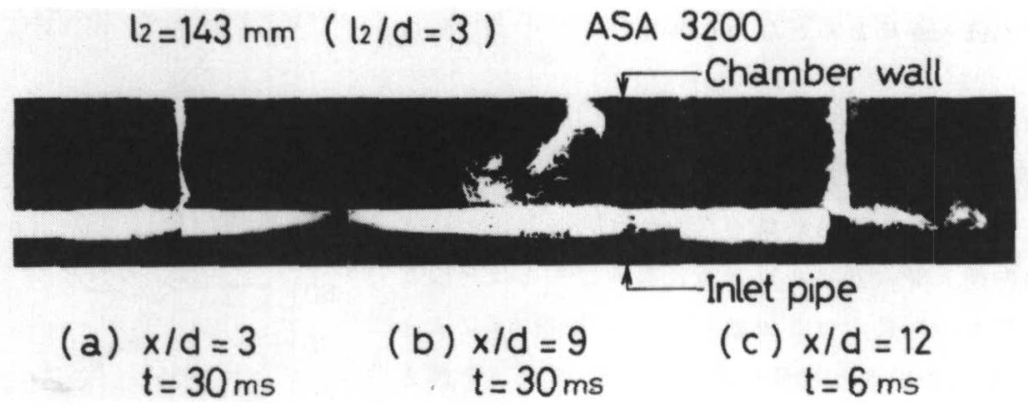

Fig. 4 Flow pattern in a chamber inserted with an jnletpipe by smoke-wire method.

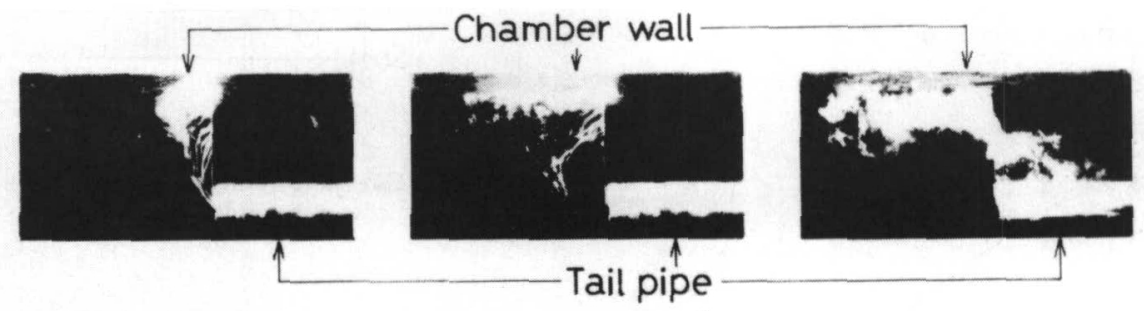
(a) $l_{2} / d=12, t=25 \mathrm{~ms}$
(b) $l_{2} / d=12, t=30 \mathrm{~ms}$
(c) $l_{2} / d=3, t=15 \mathrm{~ms}$

Fig. 5 Flow pattern in chambers inserted with a tailpipe by smoke-wire method. 


\section{$2 \cdot 2$ 気港竟スベクトル}

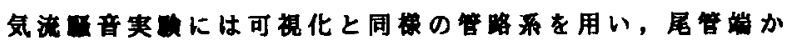

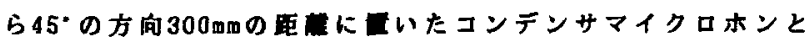

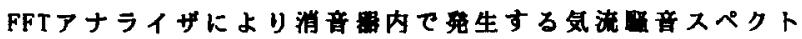

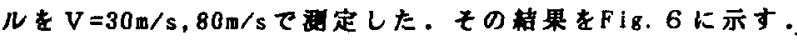

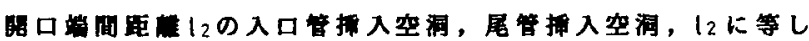

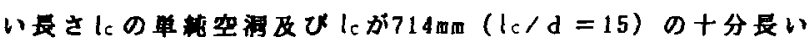

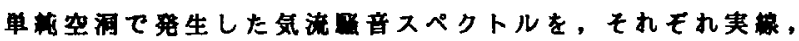

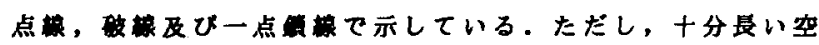

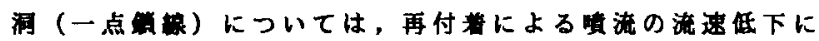
よって消音器を抑入しない合の尾管蝡からの吹出し音と顆 做のスペクトルになっている，12/dを12，9，6と変化させ

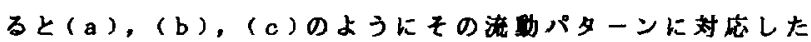
スペクトル変化を示している。しかし，尾管捅入空洞では他 の空洞にくらへて全測定周波数城にわたり6〜10dBの增加が 躇められる。このレベル增加はFig. 5 (

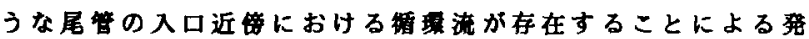
生音に起因するものと考えられる．これに対しFig. 6(d)の 12/d=3の合にピーク成分は，低流速では消盖器形状が罢 なっても一致しており，高速になるとピーク閑波数がずれる。 また他の周波数成分についてはFig. 6 ( a ) 〜 ( c)くらベてレ ペル増加は小さくなっている。これらのスペクトルに現われ るピーク成分は流外泩成する佩の直整によるもので(2) またレベル增加が小さいことはFig. 5 (c)に示したように尾 管への犆理流の流入がほとんど塱められないことによるもの と考えられる。

\section{3. 站 胥}

掄入管のある空淍形消音器内の流九を可視化し，気流品音 スペクトルを湖定した。その赫果から次のことがわた。

（1）空满内捅入管（西徍d）と消音器入口または出口と

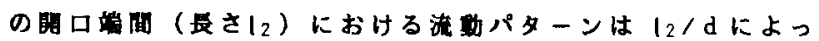

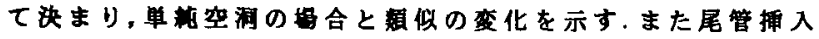

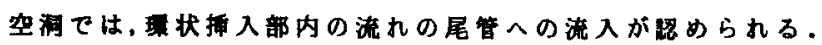

（2）尾管㧫入空洞で発生する気流音スペクトルは単耗 空洞，入口管捅入空洞の合にくらへて $12 / \mathrm{d}$ がさいとき

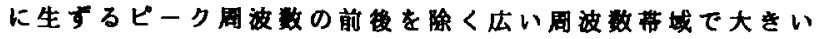
レヘルを示す。

㸼りに本研究を行うにあたりこ咕力いただいた，東海大学

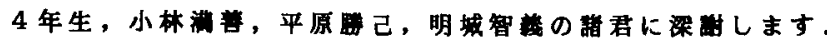

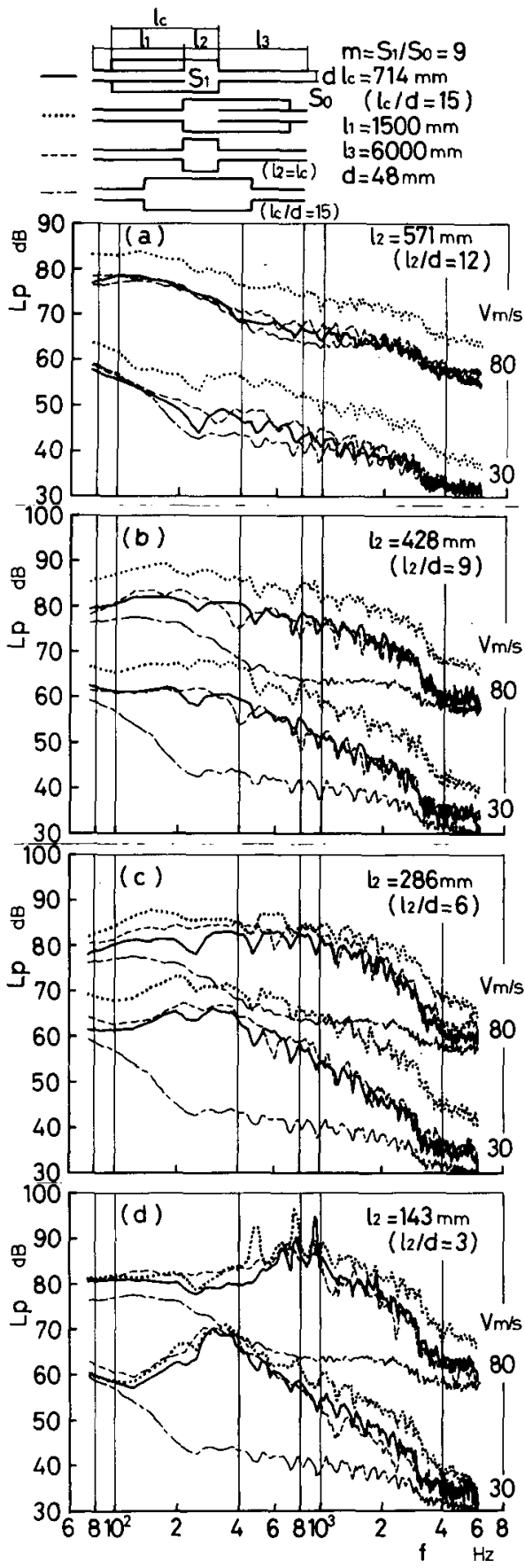

Fig. 6 Spectra of noise generated by flow in chambers.

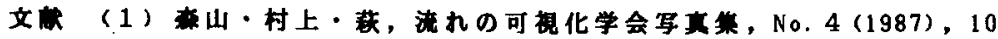

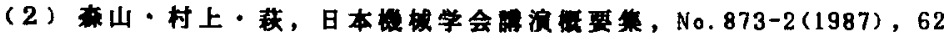

